National Aeronautics and Space Admınıstratıon

\title{
Press Kit
}

RELEASE NO: $81-106$

\section{Contents}

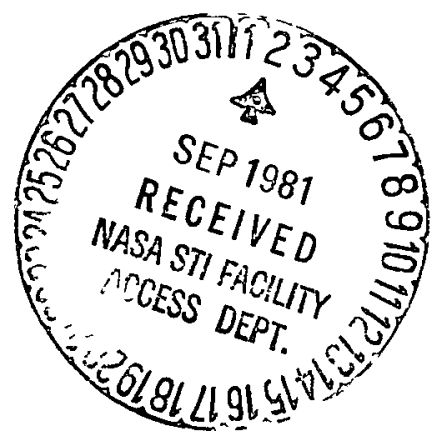

GENERAL RELEASE .......................... 1

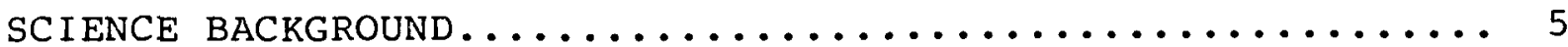

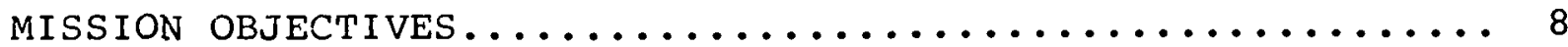

SPACECRAFT DESCRIPTION ...................... 8

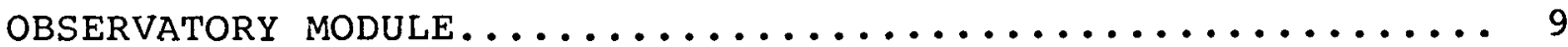

SPACECRAFT BUS ............................11

GROUND SEGMENT ............................. 14

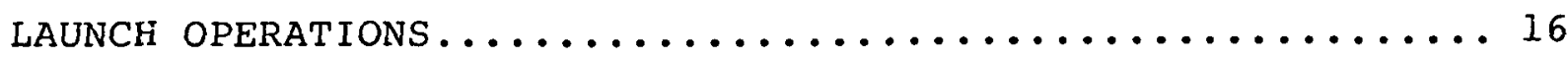

SME TEAM................................ 17

(NASA-Neys-Release-81-106) SOLAR GESOSPHERE N81-29146 EXPLORER (National Aeronautics and space Adounistration) $18 \mathrm{p}$ CSCL 22B 
Natıonal Aeronautics and Space Admınıstration

Washıngton, D C 20546

AC $202755-8370$

Charles Redmond

For Release

Headquarters, Washington, D.C.

(Phone: 202/755-3680)

Don Bane

NASA Jet Propulsion Laboratory, Pasadena, Calif.

(Phone: 213/354-5011)

RELEASE NO: $81-106$

SOLAR MESOSPHERE EXPLORER TO BE LAUNCHED SEPT. 15

The National Aeronautics and Space Administration will launch its Solar Mesosphere Explorer spacecraft into polar orbit from Vandenberg AIr Force Base, Calif., no earlier than 2:4l a.m. PDT, sept. 15, 1981.

The Solar Mesosphere Explorer is an atmospheric-research satellite designed to study reactions between sunlight, ozone and other chemicals in the atmosphere and how concentrations of ozone are transported in the atmosphere in the region from $30 \mathrm{kilo-}$ meters (19 miles) to $90 \mathrm{~km}$ ( $55 \mathrm{mi}$.$) altitude.$

At least one year of orbital operation is planned.

August 27,1981 
Five sclentific instruments will simultaneously monitor ozone and minor atmospheric-constituent quantities, water-vapor abundance and temperature, and the amount of incoming solar radiation to determine the role each plays in ozone production and distribution throughout the mesosphere. Scientific data from the mission will help to develop models for ozone production and depletion on a global scale.

(The mesosphere is the region of the atmosphere between 30 $\mathrm{km} 19 \mathrm{mi}$. and $80 \mathrm{~km} 50 \mathrm{mi}$. altıtude -- above the stratosphere and below the ionosphere. Radiation of short wavelength in that region causes a variety of photochemical reaction; the most notable is creation of a layer of ozone that effectively absorbs solar ultraviolet radiation and causes a warm layer at about 30 $\mathrm{km} 18 \mathrm{mi}$. altitude.)

The experiments are:

- An Ultraviolet Ozone Spectrometer, to measure ozone $\left(0_{3}\right)$ between $40 \mathrm{~km}(25 \mathrm{mi.})$ and $70 \mathrm{~km}(43 \mathrm{mi}$ ) altitude;

- A 1.27-micron spectrometer, to measure ozone between 50 $\mathrm{km}$ ( $31 \mathrm{mi}$. ) and $90 \mathrm{~km}$ ( $56 \mathrm{mi}$. ) altituaje, and hydroxyl (OH) between $60 \mathrm{~km}(37 \mathrm{mi.})$ and $90 \mathrm{~km}(56 \mathrm{mi}$.$) altitude;$

- A Nitrogen Dioxide spectrometer, to measure $\mathrm{NO}_{2}$ between 20 $\mathrm{km}$ ( $12 \mathrm{mi}$.$) and 40 \mathrm{~km}(25 \mathrm{mi}$.$) altitude;$

- A four-channel Infrared Radiometer, to measure temperature

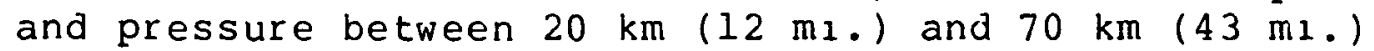
altitude; and water vapor and ozone between $30 \mathrm{~km} \mathrm{(19 \textrm {mi } . )}$ and $65 \mathrm{~km}$. (40 $\mathrm{mi}$.$) altitude;$

- A Solar Ultraviolet Monitor, to measure incoming radiation from the sun. 
The Solar Mesosphere Explorer satellite will be launched into a Sun-synchronous ( 3 a.m.-3 p.m.) circular orbit, $540 \mathrm{~km}$ (336 $\mathrm{ml}$, ) above the Earth's surface, aboard a two-stage Delta 2310 launch vehicle. (A Sun-synchronous orbit allows the spacecraft to observe any spot on Earth at the same relative local time of day.)

The satellite consists of two major moaules: the observatory Module and the spacecraft Bus. The satellite body is a cylInder 1.7 meters (69 1nches) tall by $1.25 \mathrm{~m}$ (50 in.) in diameter. The spacecraft is powered by a disk-shaped solar array $2.2 \mathrm{~m}$ (88 in.) In diameter. The solar array is fixed to the lower end of the maln cylinder, and charges nickel-cadmium batteries.

The satellite is spin-stabilized. A 5-rpm controlled spin rate stores angular momentum.

Magnetic Torquing precesses the spin axis to control roll error. The spin axis is maintained at right angles to the orbit plane. Yaw errors are sensed and corrected as roll error onequarter of an orbit later. Horizon sensors measure roll error and spin rate, and a three-axis magnetometer provides Earth magnetic-field data to a closed-loop, control-law electronics set (attitude computer) for automatic roll and spin-rate control.

The instruments are gated (open and closed) once each revoIution to gather data as their field of view sweep toward the Earth's limb in the general altitude range of $80 \mathrm{~km}(50 \mathrm{mi})$ to $20 \mathrm{~km}$ (12 $\mathrm{mi}$.$) above the limb.$ 
The Jet Propulsion Laboratory, Pasadena, Calif., manages the Solar Mesosphere Explorer project for NASA's Office of Space Sclence. Ball Aerospace Systems Division provided the spacecraft bus, satellite integration and system test. The University of Colorado's Laboratory for Atmospheric and space Physics is responsible for the science instruments, mission operations, the project operations Control Center and science data evaluation and dissemination, under contract to Jet propulsion Laboratory.

(END OF GENERAL RELEASE; BACKGROUND INFORMATION FOLLOWS.) 
Ozone is present in the Earth's atmosphere as a consequence of the photodissociation (breakdown by solar radiation) of molecular oxygen $\left(\mathrm{O}_{2}\right)$ by solar ultraviolet radiation.

Oxygen atoms $(0)$ that result from the dissociation process join with oxygen molecules $\left(\mathrm{O}_{2}\right)$ more up to form ozone $\left(\mathrm{O}_{3}\right)$. Solar radiation also acts to destroy ozone by photodissociation, particularly in middle ultraviolet. Oxygen atoms also break down ozone into molecular oxygen.

Other atmospheric constituents react with ozone, sometimes in cyclic reactions that consume ozone while they themselves are regenerated. Atomic hydrogen $(H)$ and the hydroxyl (OH) radical, the photodissociation products of water vapor, catalytically destroy ozone. Another atmospheric species that reacts catalytically to destroy ozone is nitrogen dioxide.

Water vapor occurs naturally in the atmosphere, but its abundance may vary, and this varlation will affect the density of ozone.

Nitric oxlde and nitrogen dioxide also occur naturally by the oxidation of nitrous oxide, by solar proton events, and by ionospheric reactions, but they may be injected in the atmosphere artificially as well.

Other atmospheric constituents have also been identified as catalytic destroyers of ozone. Halogens and oxides of halogens belong to this class, and their origins lie at least partly in human activities. Chlorofluoromethane, a propellant found in spray cans and refrigerants, contains chlorine, a halogen that can be transported into the stratosphere before ultraviolet radiation can photodissociate it.

The vertical distribution of ozone in the Earth's atmosphere between 40 and $80 \mathrm{~km}(25$ and $50 \mathrm{mi}$.) is determined by photochemical processes. Transport processes (vertical and horizontal mixing) are primarily responsible for the alstribution of ozone below $30 \mathrm{~km}(19 \mathrm{mi.})$ and above $80 \mathrm{~km}(50 \mathrm{mi}$.). Above $80 \mathrm{~km}(50 \mathrm{mi})$. transport controls atomic oxygen, atomic hydrogen, and thereby ozone.

In the altitude range of 40 to $80 \mathrm{~km},(25$ to $50 \mathrm{mi}$.) the amount and distribution of ozone is determined by the intensity and spectral distribution of solar ultraviolet radiation, by the abundance and distribution of minor atmospheric constituents, and by the temperature structure of the atmosphere. 


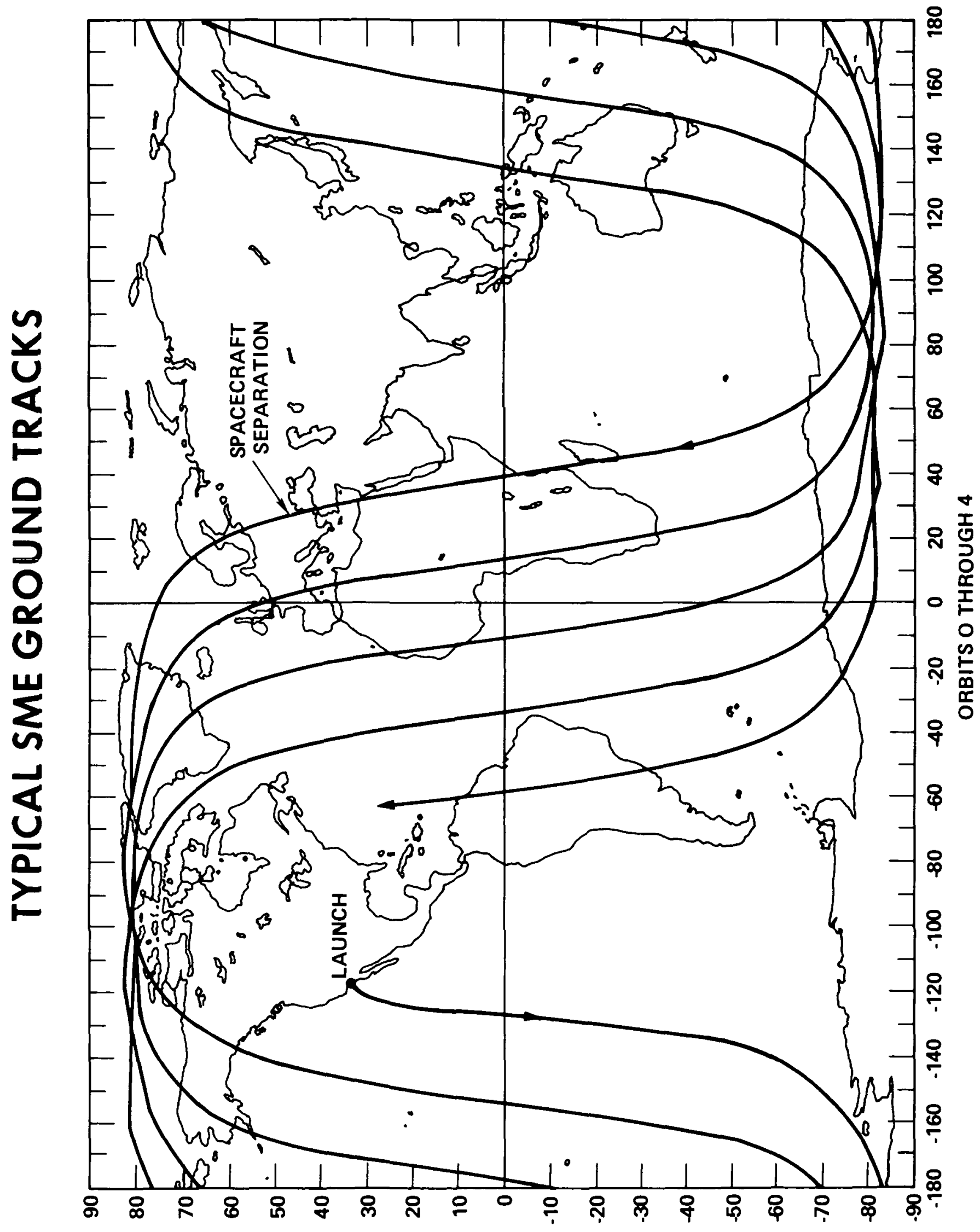




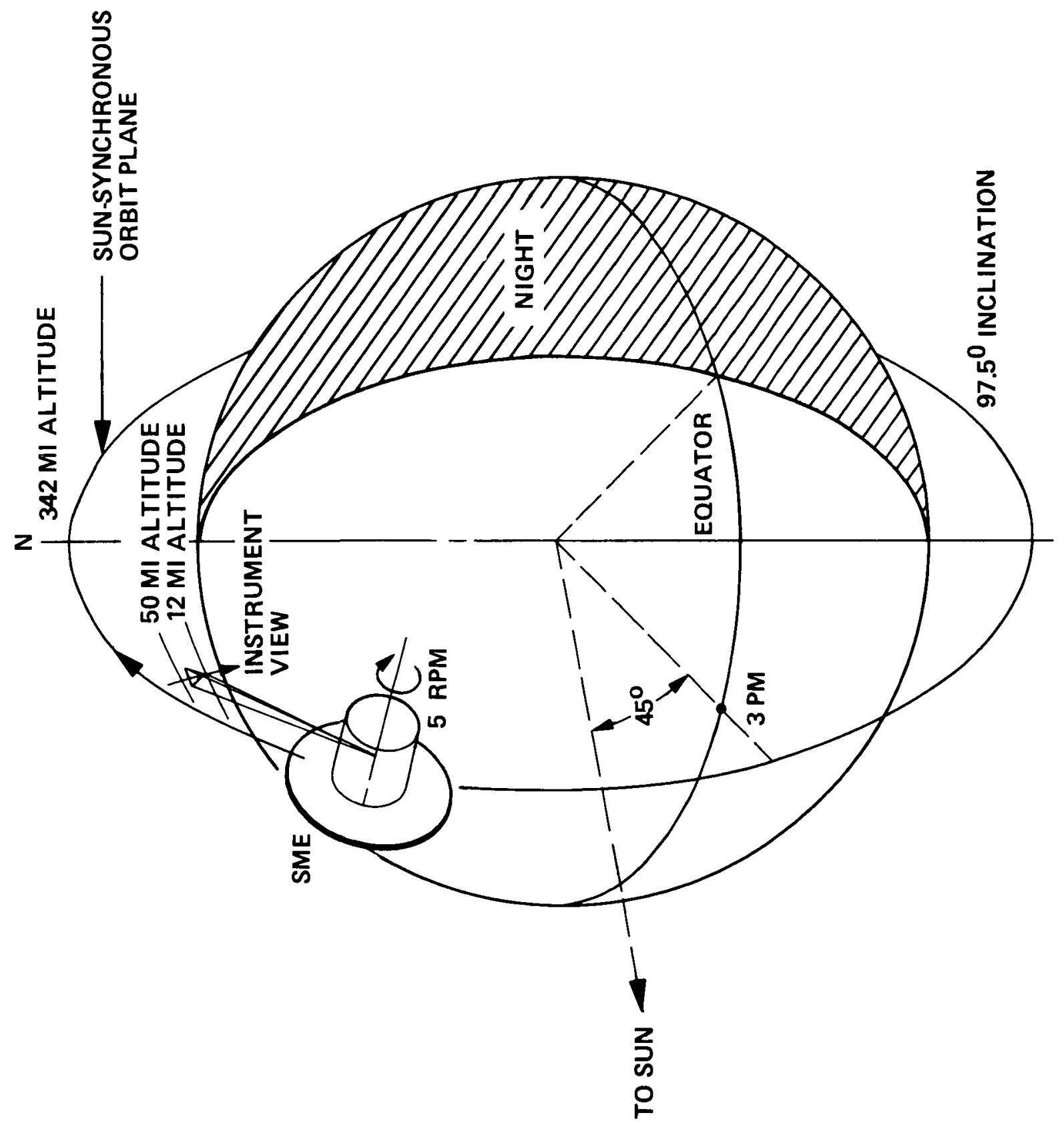




\section{MISSION OBJECTIVES}

The objectives of the Solar Miesosphere Explorer project are:

- To provide a comprehensive study of atmospheric ozne and the processes that form and aestroy it above $30 \mathrm{~km} \mathrm{(19}$ mi.);

- To determine what changes occur in ozone distribution as a result of changes in incoming solar radiation;

- To Ineasure changes in ozone density distribution in the altitude range of 30 to $90 \mathrm{~km}$ ( 19 to $56 \mathrm{mi}$.) and determine the causes of those changes;

- To measure simultaneosly temperature, pressure, water vapor, nitrogen dioxide, near-infrared airglow and the amount of incoming solar radiation;

- To determine what solar-terrestrial correlation exists and the paths that lead to changes in ozone density;

- To determine other changes in ozone abundance and distin guish them from changes caused by the sun.

\section{SPACECRAFT DESCRIPTION}

The Solar Mesosphere Explorer spacecraft consists of two major modules: the Observatory Module and the spacecraft Bus.

The satelilte body is a cylinder $1.7 \mathrm{~m}$ (69 in.) tall by 1.25 $\mathrm{m}$ (50 1n.) in diameter. The solar array is a disk located on the booster ena of the cylinder. The array is $2.2 \mathrm{~m}(88 \mathrm{ln}$.) in diameter.

The satellite is spin-stabilized. A 5-rpm controlled spin rate stores angular momentum. Magnetic torquing precesses the spin axis to control roll error. The spin axis is malntained at right angles to the orbit plane. Yaw errors are sensed and corrected as roll error one-quarter of an orbit later. Horizon sensors measure roll error and spin rate, and a three-axis magnetometer provides field direction and magnitude data to a closedloop, control-law electronic set (attitude computer) for automatic roll and spin-rate control.

Data from the rotating science instruments are gated (cycled "on") once each revolution as the instruments' fields of view sweep toward the Earth's limb in the altitude range of $80 \mathrm{~km}$ (50 $\mathrm{mi.})$ to $20 \mathrm{~km}(12 \mathrm{mi}$.) above the limb.

The satellite is powered by a solar array that charges nickel-cadimulm batteries. Voltage/temperature control is used, and an undervoltage switch guards against inadvertently depleting discharge of the batteries. 
Uplink command capability from the project Operations Control Center in Boulder, Colo., to the satellite, and downlink data communications from the satellite to the center are handled via the NASA Communications Network and Grouna-Station Tracking and Data Relay Satellite system and, when it is operational, the Tracking and Data Relay Satellite system on its s-band multipleaccess channel. Ground Station Tracking Data Network will be prime communications source until TDRSS is operational and verified as compatible with the Solar Mesosphere Explorer multipleaccess mode.

A command and data processor will format instrument and engineering data and will decode, store and issue commands. Commands may be stored for four days and issued at any time with eight-second resolution. Data are returned in real-time and from redundant tape recorder playback via Ground station Tracking Data Network or Tracking Data Relay System Network. The satellite has a near-omniảrectional command antenna pattern and a near-omnidirectional real time data downlink antenna pattern.

One high-gain antenna, on the sunlit end of the satellite, provides coverage for tape-recorded data playback via TDRSS twice each 24 hours as the two TDRSS satellites transit the solar Mesosphere Explorer spin-axis direction.

A NASA standard transponder is used for receiving commands, downlinking data, and tracking.

The satellite has passive thermal control, using painted surfaces, tape surfaces, multilayer insulation blankets and heaters. The orbit plane stays at 45 degrees to the Sun direction ( 3 a.m.3 p.m. Sun-synchronous orbit) so that the spinning satellite-sunEarth geometry is nearly fixed.

The satellite does not have a propulsion system or pyrotechnic devices. The radiator for the infrared radiometer instrument has a cover that is jettisoned in orbit. The radiometer also has an aperture cover that may be closed by command for occasional calibration on-orbit.

\section{OBSERVATORY MODULE}

The Solar Mesosphere Explorer payload consists of five experiment packages. Two sets of engineering sensors provide auxiliary information. Four of the instruments -- ultraviolet ozone, 1.27-micron airglow, visible nitrogen dioxide and infrared radiometer -- will view at right angles to the spacecraft spin axis. Those four instruments scan through the limb twice each spacecraft rotation.

The four limb-scanning instruments will measure all parameters required for analysis of the ozone photochemistry. 


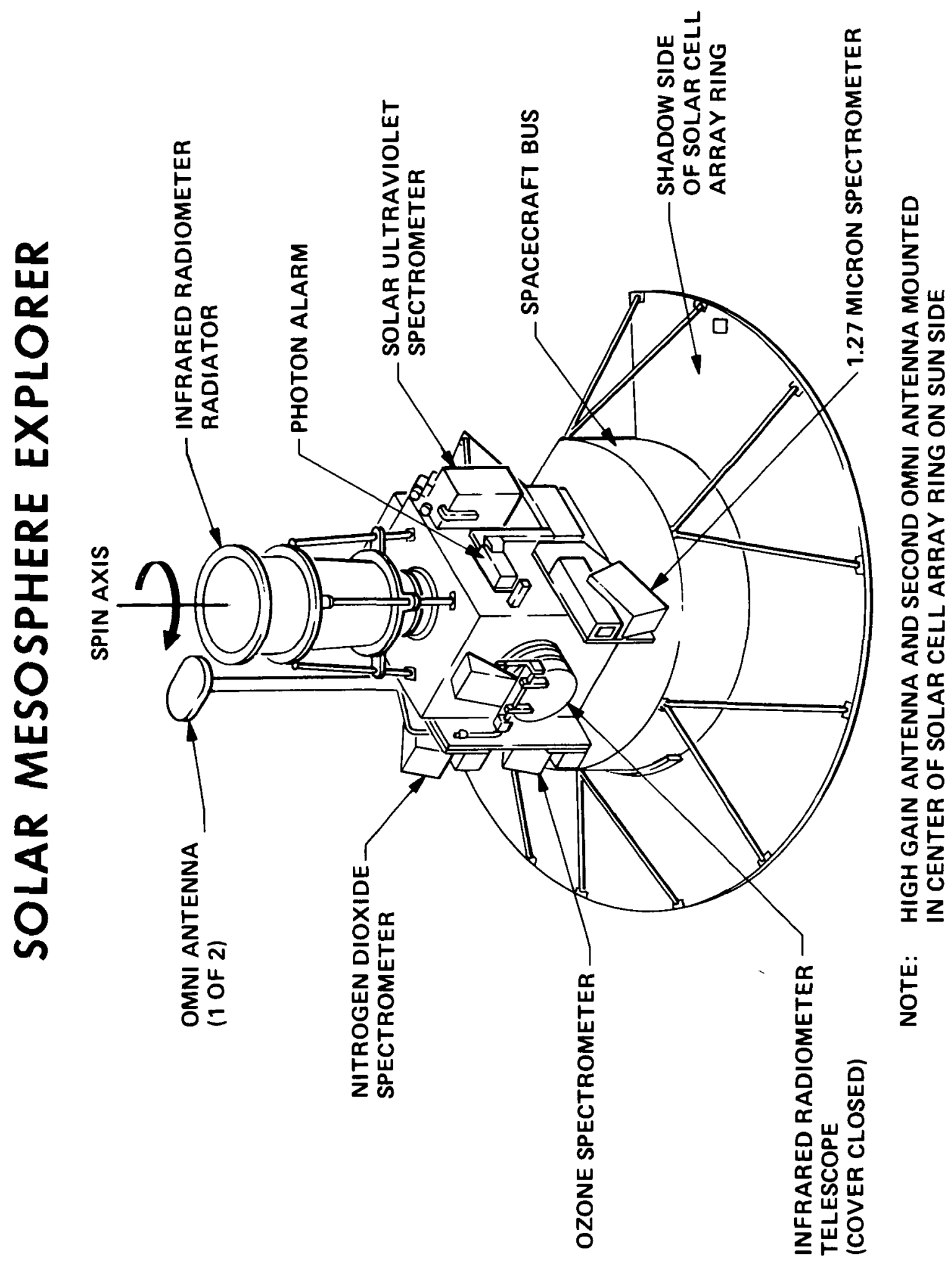


The ultraviolet ozone spectrometer measures ozone between 40 $\mathrm{km}(25 \mathrm{ml}$.$) and 70 \mathrm{~km}(43 \mathrm{ml}$.$) altitude; the 1.27-\mathrm{micron}$ spectrometer measures ozone between $50 \mathrm{~km}(31 \mathrm{mI.})$ and $90 \mathrm{~km}(55 \mathrm{mi.})$ altitude, and hydroxyl between $60 \mathrm{~km}(37 \mathrm{ml}$.$) and 90 \mathrm{~km}(57 \mathrm{ml}$. altitude; the Nitrogen Dioxide spectrometer measures $\mathrm{NO}_{2}$ between $20 \mathrm{~km}(12 \mathrm{ml.})$ and $40 \mathrm{~km}(25 \mathrm{ml}$.$) altitude; the four-channel$ Infrared Radiometer measures temperature and pressure between 20 $\mathrm{km}(12 \mathrm{ml}$.$) and 70 \mathrm{~km}(43 \mathrm{ml}$.$) altitude; and water vapor arid$ ozone between $30 \mathrm{~km}(19 \mathrm{mi}$.$) and 65 \mathrm{~km}(40 \mathrm{mi.})$ altitude.

The fifth instrument, the ultraviolet solar monitor looks 45 degrees from the spacecraft rotation axis, so that, in the 3 a.m.$3 \mathrm{p} . \mathrm{m}$. Sun-synchronous orbit, the instrument will scan through the sun once each revolution of the spacecraft. The instrument will measure the amount of lncoming solar radiation from 1,700 Angstroms to 3,100 angstroms, and at 1,216 Angstroms.

Two engineering devices support operation of the five science instruments. A proton alarm sensor monitors the amount of integrated solar protons in the range from 30 to 500 million electron volts (Mev). A command-selectable proton-level trigger puts the experiment complement in a preselected active sun observing mode when proton flux exceeds the trigger level. The proton alarm mode sequencing regime is stored in onboard memory as a block of timed commanas.

A spatial reference unit, actuated by iimb-crossing pulses from the satellite horizon-crossing indicators, control the timing for data gating from the instruments. The reference system is command-adinitted to select the altitude range of viewing for each instrument and contains a clock for altitude increments for which data are gated.

\section{SPACECRAFT BUS}

The mechanical subsystem provides structural mounting platforms for the satellite engineering components and harness, the Observatory Module instrument complement, and the solar array. The subsystem also provides the Delta Launch vehicle attach fitting.

The spacecraft Bus combines a .93-m (37-in.) Delta vehicle adapter ring, three vertical spars on a .93-m (37-in.) diameter that carry loads to the booster adapter from the interface plate that mounts the Observatory Module, three vertical equipmentmounting plates that span the spars, and a horizontal lower equipment mounting plate just above the attach fitting that, together with the interface plate, closes out the three-sided box formed by the basic structure.

The Observatory Module interface plate and the lower plate are circular and carry the outer thermal-control surfaces so that the Bus outer shell is a cylinder. The fixed annular solar array honeycomb substrate is made from two symmetrical pieces. 
The array honeycomb substrate is made from two symmetrical pieces. The array is attached at the lower plate and bracketsupported from the box structure.

The Observatory Module basic structure is a box made from heavy aluminum plate. The box accommodates the infrared radiometer on the inside and provides mounting for the other instruments on the outside.

The Observatory Module mounts to the interface plate pads, and the interface plate mounts to the bus spar hard points with three pads. Mounting pads on the bus are insulated so the bus and Observatory Module interface-plate combination are nearly thermally independent.

Electric Power Subsystem

The electric power subsystem is a conventional, full-shunt, direct-energy-transfer system supplying unregulated DC power at 25 to 31.5 volts. The solar array consists of 2,156 cells in 28 strings of $10-\mathrm{ohm} / \mathrm{cm}$, each 2 by 4 centimeters (.78 to 1.6 in.), mounted on an annular honeycomb substrate of 4,000 square inches (88 $\mathrm{in}$.) outer dlameter and $44 \mathrm{in}$. inner diameter). The array prouluces 4.8 amps at the nominal 45-degree angle of incidence.

Two batteries, with 2l, six-amp-hour nickel cadimuim cells each, store energy for operation during the occulted portion of each orbit anci for high-power-usage periods.

Battery charge is controlled by voltage/temperature-controlled shunt regulator using four voltage/temperature rates individually selectable by command.

Battery depth-of-discharge is nominally less than 20 percent. An undervoltage switch protects the system against inadvertent high current or low voltage conditions.

A load bank dissipates the solar array current when the batteries reach full charge.

Attitude Control Subsystem

The attitude-control subsystem keeps the spin axis at 90 degrees to the orbit plane, limits nutation to less than 0.1 degree, mantains spin rate at $5 \mathrm{rpm}$, and generates a stable limb-reference pulse for Observatory Module instrument data gating.

The system uses a fixed-horizon sensor $V$ palr rotating with the satelite to measure spin-axis position and spin rate. A three-axis magnetometer is orlented so that 1 ts sensitive axes are aligned with the velocity vector, 90 degrees to the orbit, and nadir at the time the horizon sensor encounters the horizon. 
The magnetometer is samplea at that instant and the magnetic field values, together with roll- and spin-rate error values, are fed to control-law electronic.

A magnet aligned with the spin axis is switched by the control-law electronics to torque (precess) the satellite to reduce any roll error when the field direction is proper. Another magnet, at right angles to the spin axis, is switched by the controllaw electronics to reduce any spin-rate error when the field direction is proper. A fluid-filled-ring nutation damper absorbs energy to reduce nutation.

A processed limb pulse from the horizon sensors is sent to the instruments so that gating occurs when the instruments are viewing the altitude that is of interest.

The control system is autonomous and requires no ground control. Ground-control adjustment of the instrument data gate times relative to the horizon reference pulse allows full adjustment of the altitude of the experiment data acquisition.

Command anä Data-Handling Subsystem

The command and data-handling subsystem recieves, decodes and distributes commands, formats digital and analog data, stores commanás for later time-tagged execution, and stores data on tape for later downlink transmission.

The system consists of a command decoder, a digital telemetry unit, two redundant tape recorders, and a telemetry distribution unit that serves to interface the control-and-data-handIIng units and the transponder that is part of the communications subsystems.

The telemetry system has four formats, each of which has 128 eight-bit words as a minor frame. The real-time bit rate is 512 bits per second so that each minor frame is two seconds long. There are 14 subcommutators. Four subcoms, four words deep, provide an elght-second sample-rate capability. One subcom, elght words deep, provides a 16-second sample-rate capability; and nine subcoms, 16 words deep, provide 32-second sample-rate capability.

The four formats are command selectable and consist of a primary operating format for normal operations, a stored-command memory-dump format to confirm the stored command load, a secondary science format, and a high-rate englneering format for orbit initialization, testing and troubleshooting.

Each tape recorder stores 16 million bits of data. The playback rate is 8,192 bits per second. The command-storage capability is 512 sixteen-bit command words. Commands may be stored for up to 96 hours and executed with eight-second resolution. A command block in memory provides for storage of a proton-alarm sequence so the instrument can specifically observe solar-flare effects on the ozone layer. 


\section{Communications Subsystem}

The communications subsystem uses the NASA standard Ground System Tracking Data Network/Tracking Data Relay System transponder for uplink command reception, downlink telemetry transmission and tracking by coherent transponding of ranging signals.

The transponder has a 5-watt transmitter. The Tracking Data Relay system multiple-access downlink is used.

An omnl-directional antenna pattern is produced by two hemispherical pattern antennas, one on each end of the satellite, for command reception.

Hemispherical antenna patterns produced by command-selectable antennas are used for real-time (512-bps) data downlink via Tracking Data Relay system and for simultaneous real-time and tape-recorded playback (8,192 bps) data downlink via Ground system Tracking Data Network.

One high-gain antenna located on the sun side of the satel1 ite is used to transmit the tape recorded data whenever a Tracking Data Relay system is near the spin axis of the solar Mesosphere Explorer. Data are transmited either in the real time or from the tape recorder in simultaneous real-time and taperecorder playback. Commands are uplink at 125 bits per second.

The satellite is operated from a Project operations Control Center located at the Laboratory for Atmospheric and Space Physics at Boulder, Colorado, that ties to NASCOM using links from Boulder to Goddard Space Flight Center Greenbelt, Md.

\section{GROUND SEGMENT}

The Mission Operations System is located at the project operation Control Center at the Laboratory for Atmospheric and space Physics.

From there, satellite control functions are controlled, experiment operations are coordinated, Spacecraft Bus and observatory Module performance verified, and ground communications systems coordinated.

Commands for real-time execution and command-memory loading initated at the control center are transmitted via links to NASCOM through Goddard to the GSTDN TDRSS sites for direct uplink. to the satelilte. Real-time commands are required both by the science team, to optimize the Observatory Module configuration. and the engineering team to control satellite subsystems.

On-board command memory loads, prepared by the Command Memory Management and sequencing system, are based on orbit-event prediction, engineering requirements, and on the scientificexperiment observing requests. 
The Command Memory Management and Sequencing System receives inputs and prepares a time-ordered, error-free, bit-structured command memory load synchronized with schedulea Ground-station Tracking and Data Relay Satellite Network contacts.

Experiment observing sequences are planned by the scientific investigators based on the major sclentific mission objectives and priorities, the current condition of the sun as monitored and reported by the space Environmental Services Center in Boulder, and results of current Solar Mesosphere Explorer observations. The task requests to support the observations are then scheduled by the science and mission planners according to the predicted timeline of orbital events.

Real-time and tape-recorded playback data are downlinked via Ground Station Tracking Data Network/Tracking Data Relay Satellite system and transmittd in real-time to the project operation Control Center via NASCOM system. The real-time data are used for command verification, quick evaluation of scientific operation, and spacecraft and instrument performance checks. The tape recorder playback data are used for detailed spacecraft and instrument performance checks, quick-look scientific evaluation, and in-depth scientific analysis.

Both real-time and tape-recorded playback data, received at the Project operation Control Center, are processed and avallable within hours to the Mission and Sclence Analysis Subsystems for interactive data analysis.

Initial processing is done by Mission Data Processing to convert the data into science format, the check for errors in the tape playback data, to correct experiment times, to determine satellite attitude, and to process the orbit parameters. Processed data are included in the Mission Data-Base Management system.

Scientists and mission analysts access formatted data from the Mission Data-Base System using an Interactive Data Language that allows them to edit, manipulate, display and plot the data. Results of the quick evaluation serve as inputs for the next day's experiment plan.

The interactive system is also used for in-depth analysis where the Interactive Data Language, along with system and userwritten procedures, enables the scientist and mission analysts to process and correlate large amounts of Solar Mesosphere Explorer data.

Tracking data are transmitted from Ground station Tracking Data Network to the Orbit Determination Division at Goddard for computation of definitive orbit parameters. 
The definitive and predicted orbit parameters and stationcontact times are determined and made avallable to the Laboratory for Atmospheric and space Physics project center in Boulder two to three times a week for science data identification and experiment planning.

The Project Operation Control Center hardware is controlled by a PDP $11 / 34$ computer with a floating point processor.

The Project Operation Control Center system recelves and records telemetry äata, formulates sends, and verifies command sequences, monitors and displays satellite health data, correlates the sateli ite clock to Greenwich Mean Time, forwards telemetry data to science analysis system, interfaces with Goddard's Network Control Center for network scheduling, interfaces with Goddard's Orbit Determination and Prediction Facillty, and records all data and command activity for the satellite operations $\log$.

The Project Operations Control Center is used before Iaunch for testing the observatory Module with the spacecraft simulator, for spacecraft Bus and network compatibility checkout, and for training operators for on-orbit mission operations.

\section{LAUNCH OPERATIONS}

Launch operations from NASA's west coast facility are conducted by the Kennedy Space Center's Expendable Vehicles Operations Directorate. This facility is located at the Western space and Missile Center, Vandenberg Air Force Base, near Lompoc, Calif., approximately $200 \mathrm{~km}(125 \mathrm{ml}$.) northwest of Los Angeles and $450 \mathrm{~km}(280 \mathrm{mi}$.) south of San Francisco. Launch facilities are located on a promontory which juts into the Pacific Ocean near Point Arguello, making it possible to launch to the south to place payloads into polar orbit without overflying populated areas.

Solar Mesospheric Explorer (SME) will be launched aboard Delta 156 from space Complex Two West (SLC-2W), which has been extensively updated over the years to accept the various Delta configuations.

Some KSC personnel are on permanent assignment as members of the Delta Wester Operations Branch. These personnel are augmented by a larger management and technical group from the Kennedy space Center in Florida during final preparations and the launch countdown.

A permanent work force is maintalned at these facilities by the McDonnell Douglas Corp., prime contractor for the Delta launch vehicle. 
Preparation for the Solar Mesosphere Explorer launch began Aug. 4 with the erection of the Delta 156 booster at SLC-2W. The interstage was erection Aug. 5 .

Three Castor II solid rocket motors were mounted around the base of the booster stage on Aug. 6 and the second stage was mounted with the booster on Aug. 7 .

The spacecraft arrived Aug. 16 and was tested and checked out in the spacecraft Checkout Laboratory. It is scheduled for movement to the launch pad on september 1 for mating with the Delta second stage. The payload fairing, which will protect the spacecraft on its flight through the atmosphere, is scheduled for installation on september 8 .

\section{SME TEAM}

NASA Headguarters

Andrew J. Stof an

Dr. Jeffrey D. Rosendahl

Dr. Franklin D. Martin

J. Warren Keller

Rlchard E. Halpern

Marıus Weinrab

Kennedy space Center

Richard G. Smith

Thomas S. Walton

Charles D. Gay

Wayne L. McCall

Ray Kimlinger

E. J. Langenfeld
Assoclate Administrator for Space Sclence (Acting)

Assistant Associate Administrator space Science (Acting)

Director, Solar Terrestrial and Astrophysics Division

Deputy Director, Solar Terrestrial and Astrophysics Division

Manager, Research Flight Programs Development

Program Manager, Solar Mesophere Explorer

Director

Director, Cargo Operations

Director, Expendable Vehicles Operations Directorate

Chief, Delta Operations

Division

Chief, Delta Western Operation Branch

Spacecraft Coordinator 
Jet Propulsion Laboratory

Dr. Bruce C. Murray Director

Gen. Charles A. Terhune Jr. Deputy Director

Robert J. Parks

Assistant Director for Flight Projects

John Paulson

Project Manager

Dr. James stuart

Deputy Project Manager

Kathleen Lee

Resources Documentation Control Manager

University of Colorado (Boulder)

Laboratory for Atmospheric and Space Physics

Dr. Charles Barth

Principal Investigator

Lowell Dorman

Observatory Moaule Manager

Elaine Hansen

Mission Operations Manager

Ball Aerospace Systems Division (Boulder)

John Simpson

Program Nanager

Ron Brown

Deputy Program Manager

- enā-

(Index: 29,36 ) 